\title{
Autoria feminina no século XIX: \\ a vida e obra de Ana Augusta Plácido
}

\author{
Maria Luísa Taborda Santiago ${ }^{1}$ \\ doi.org/10.47585/nemtudosaorosas8
}




\section{Introdução}

Ana Augusta Plácido nasceu na cidade do Porto em 27 de dezembro de 1831, filha do comerciante António José Plácido Braga e Dona Ana Augusta Vieira. Casou-se, obrigada pelo pai, aos 19 anos com Manuel Pinheiro Alves um rico comerciante brasileiro de torna-viagem, vinte e quatro anos mais velho do que ela. Apesar de ser contra a imposição do pai, Ana Plácido não tinha alternativas já que naquela altura as meninas eram preparadas apenas para este destino. De acordo com Maria Amélia Campos (2008):

Ana Plácido cresceu e foi educada no seio de uma família da alta burguesia portuense, cuja estrutura familiar reproduzia o modelo da época, um núcleo irredutível comandado pelo chefe da família, que determinava, desde o berço, o trilho da prole que o destino the havia confiado. (CAMPOS, 2008, p. 37).

O casamento com Manuel Pinheiro Alves foi mantido durante oito anos em nome dos costumes morais daquela época: "obedeci forçada pelas circunstâncias a aceitar-te por esposo [...] O inesperado do seu casamento, a pronunciada antipatia que sempre sentira pelo homem que diante de Deus lhe chamava sua" (PLÁCIDO, 1995, p. 76). Ao fim destes oito anos Ana Plácido já era órfã de pai e mãe e já havia perdido sua irmã mais querida Maria José, para a qual dedicou a sua primeira publicação Luz Coada por Ferros. É neste contexto que Ana Plácido abandona o marido para viver com sua grande paixão, o escritor Camilo Castelo Branco.

Pinheiro Alves bastante indignado com a traição da esposa e muito preocupado com os escândalos que aquela situação lhe poderia causar, decide então por enclausurar a esposa num convento em Braga. O tempo de clausura conventual, contudo, não dura muito e Ana Plácido foge mais uma vez para ir viver com Camilo.
Nesta época, em Portugal, o adultério era considerado crime, Camilo Castelo Branco e Ana Augusta Plácido são então denunciados por Pinheiro Alves e assim recolhidos para a Cadeia de Relação no Porto. Este tempo na prisão, embora difícil e bastante traumático, será fundamental para a produção literária de Ana Plácido, pois é quando a escritora está livre dos afazeres domésticos que o casamento lhe impunha e pode dedicar-se apenas a literatura. Além disto, o tempo de reclusão se torna também um tempo para reflexão: a escritora afirma a sua história e reflete acerca das questões que a levaram para a prisão. De acordo com o jornal O Nacional, de 8 de junho de 1860, a cela de Ana Plácido foi mobiliada com "um piano, uma mesa de pinho com muitos livros, dentre os quais uma Bíblia, papel e tinteiro". importante ressaltar que do casamento de Plácido com Pinheiro Alves nasceu o filho, Manuel Pinheiro Alves, e que mãe e filho foram ambos recolhidos a Cadeia da Relação e por lá estiveram durante o período de quase dois anos. De acordo com Cláudia Pazos Alonso (2012):

protegeram-na do quotidiano doméstico de uma mulher da classe média/alta e das dificuldades financeiras que posteriormente viriam a ser uma constante da vida com Camilo. Dito de outro modo a prisão assegurou-lhe o tal quarto só seu², ou seja, um espaço propício à reflexão que potenciou o desenvolvimento de uma aguda consciência literária. (ALONSO, 2014, p. 242, grifo nosso).

Após serem absolvidos Ana e Camilo começam a construir uma vida juntos e têm mais dois filhos. Aos poucos a escritora passa a se dedicar aos afazeres do lar, dos cuidados com as crianças e com o marido, mantendo-se bastante afastada da literatura durante a o período que compreende principalmente a infância dos filhos, como nos explica Maria Amélia Campos (2008): "totalmente absorvida em acompanhar a aprendizagem dos filhos, não se conhece de Ana qualquer trabalho escrito, relativamente a este período" (CAMPOS, 2008, p. 199). Apesar deste afastamento cremos que a literatura ocupou papel central na vida de na obra de Ana Plácido e que sua produção literária está

2 Referência a obra de Virgínia Wool Um Teto Todo Seu “[...] uma mulher precisa ter dinheiro e um teto todo seu, um espaço próprio, se quiser escrever fiç̧ão" (WOOLF, 2014, p. 15). 
bastante marcada pela sua condição feminina, de ser uma mulher escritora num século em que as atividades intelectuais eram restritas aos homens.

Pretendemos neste estudo fazer um breve recorte sobre a vida e a obra de Ana Plácido, debatendo sobre a sua experiência como escritora e sua produção literária no século XIX.

\section{A produção literária de Ana Plácido}

Em sua primeira obra Luz Coada por Ferros, Ana Plácido se assume escritora publicando o livro sem uso de pseudónimos ou siglas como fará nas publicações a seguir. Nesta primeira obra debate sobre temas bastante relevantes para as mulheres daquela época, usa de sua experiência para narrar acontecimentos e dar vida e voz para outras personagens. O tema do casamento é uma das constantes, em tom confessional Ana Plácido volta-se para a fase de sua adolescência e reflete acerca da imposição do casamento: "nesta idade feliz, a primeira das virtudes é a obediência. Trespassam-te a um homem repulsivo, quando mal conheces a magnitude do sacrifício e o valor da mercancia" (PLÁCIDO, 1995, p. 63), "sacrificada a um homem repelente, que só me inspirava aversão vi os meus anos mais belos passarem-se tristes e na solidão forçada a que me condenaram" (PLÁCIDO, 1995, p. 66). Através da linguagem utilizada pela escritora, podemos perceber a sua lucidez e consciência, apontando que as meninas desta época estavam a ser utilizadas como moeda de troca patrimonial, o contrato matrimonial estabelecido entre o pai e o futuro marido era um contrato econômico "Quando te é dado compreender a melancólica existência, a que te condena a cobiça previdente de um pai cuidadoso em demasia [...] é já tarde...” (PLÁCIDO, 1995, p. 62)

Ainda em Luz coada por Ferros, mais especificamente no capítulo 'Meditações', podemos notar o seu processo de produção artística a crescer consoante as reflexões que faz sobre os acontecimentos que a levaram para a prisão. Cremos que é durante este tempo de reclusão que Ana Plácido começa a formar a sua consciência enquanto escritora: sujeito feminino que usa a escrita para tomar consciência de si e do papel coletivo que advém dessa consciência.
Podemos ainda identificar, que a literatura de Ana Plácido, neste período, está fortemente marcada pela sua condição feminina, de ser uma mulher escritora e uma escritora-adúltera num século em que as mulheres se viam privadas da visibilidade 'pública' da sua atividade intelectual e num contexto em que o adultério era um crime com consequências 'públicas' muito mais severas para as mulheres.

Além da escrita, a leitura ocupava os dias de Ana Plácido na Cadeia de Relação, esta ocupação é também narrada em 'Meditações':

Sinto-me endoudecer de amores, pelo autor dos Lusiadas, por Garrett, e por tantos outros nomes ilustres, que a minha fantasia se recreia em ver alindados de primores talvez desconhecidos. [...] Compenetro-me sedenta e faminta de cada nova creação de Alexandre Herculano, Mendes Leal e Castilho (PLÁCIDO, 1995, p. 86).

Outro aspecto relevante deve-se ao seu estado de consciência social e da sua situação enquanto mulher portuguesa do século XIX. Em um capítulo de sua autobiografia Ana Plácido enfrenta a sociedade que a condena por simplesmente ter decidido tomar as rédeas da própria vida, libertar-se de um casamento contra a sua vontade para estar com o homem que realmente amava: "Que venha a adversidade, que venha a desgraça com todo o cortejo das fúrias raivosas que nos malquistaram com a hipocrisia da época; que nos subvertam as tormentas que rebentam sobre a cabeça pendida. (PLÁCIDO, 1995, p. 82).

Apesar de ser a frente do seu tempo e ousar em muitos sentidos, como por exemplo, o seu "à vontade com que se punha a fumar seu charuto à janela de sua cela na Cadeia da Relação, sob a incrédula perplexidade dos transeuntes", tudo no "intuito de chocar e desafiar a opinião pública" (CAMPOS, 2008; p. 75) Ana Plácido carrega até o presente momento as marcas do passado que a aprisionam à sombra do escritor Camilo Castelo Branco, é muito conhecida pelo seu relacionamento, mas poucos sabem sobre sua produção artística. De acordo com Fernanda Cabral: 
Ana Plácido viu-se esmagada pela própria experiência romanesca. O seu nome se autonomizou. Permaneceu sempre associado ao de Camilo. Ana Plácido encarnou sempre o papel de protagonista de uma bela história de paixão e amor. A sua personalidade e o seu talento ainda aguardam que lhe façam justiça. (CABRAL, 1991, p. 20).

Ambicionava na literatura "se libertar pela escrita com o desejo de conquistar um nome literário" (CABRAL, 1991, p. 24), desta forma produziu e publicou obras que, entretanto, até hoje, seguem a sombra de um passado em que o intelectual feminino era bastante subestimado. "É esta febre que as mulheres de Portugal apagam no regelo do coração, rebatendo assim o estímulo mais atraente da ambição da glória, a única que eu invejo e aprecio". (PLÁCIDO, 1995, p. 81).

A narradora invoca as mulheres de Portugal para que se desliguem "de certas apreensões, procurando no livro e no estudo de bons mestres um refrigério para os tristonhos dias da velhice" (PLÁCIDO, 1995 p. 90). Ana Plácido refere-se ao preconceito, já exemplificado anteriormente, em que as mulheres que ousam ter algum pensamento crítico enfrentavam. $O$ tempo de reclusão foi a possibilidade de pensar, discutir e inclusive lançar um pensamento extremamente subversivo para a época:

Sei que não podemos aspirar a um nome distinto como o de madame Staël, ou Georges Sand. A estas dotou-as a subtileza do engenho, a grandeza do gênio, a vivacidade sublime que não possuímos desde que a marquesa de Alorna, e Catharina Balsemão passaram sem herdeiras. Não dêmos ao homem a fácil vitória da nossa inercia. Entremos desassombradas n'esse trilho em que os mesmos espinhos nos fazem esquecer outras dores. (PLACIDO, 1905 p. 91-2, grifo nosso).

Sua consciência do papel coletivo da mulher na sociedade portuguesa do século XIX ganha forma, para Cabral (1995) "Ana Plácido se constrói como mito de si mesma e paradigma para as outras mulheres” (CABRAL, 1995, p. 25).

Ao sair da cadeia de relação a autora continua exercendo o ofício e dedicando-se a literatura, contudo devido à pressão social por ser uma mulher-adúltera, passa a fazer uso de pseudônimos masculinos e assinar seus escritos com a sigla A.A. Cremos que este necessário uso de pseudônimos pode ter contribuído para o seu apagamento, já que sua obra atualmente ainda se encontra dispersa e pouco estudada. De acordo com Claudia Passos Alonso (2015):

Cento e cinquenta anos passaram desde o encarceramento, em 1860, do casal de literatos mais famoso do século XIX por motivo de adultério. Camilo Castelo Branco e Ana Plácido foram finalmente julgados e absolvidos após mais de um ano de cárcere, em outubro de 1861. Posteriormente ambos viriam a publicar escritor resultantes da estadia na prisão, bem como romances enquadrados pela experiência de seu «amor de perdição». É, por conseguinte, um equívoco lembrar Ana Plácido meramente através de um papel secundário tipicamente feminino, como a musa do grande gênio romântico, sem o devido reconhecimento da sua trajetória como escritora. Porém, esta é a imagem que tem prevalecido na história literária até aos dias de hoje. (ALONSO, 2014, p. 39).

Como podemos notar, além das suas condições sociais e das dificuldades em ocupar um espaço tipicamente masculino, o relacionamento com Camilo Castelo Branco também contribuiu para seu apagamento. De acordo com Paulo Motta Oliveira: "Ana sofreu um duplo rebaixamento: era uma mulher em um universo masculino, o da escrita, e foi a musa de um grande escritor, tendo, assim o seu papel como escritora praticamente apagado." (OLIVEIRA, 2018, p.48).

Em 1868, Ana Plácido participou do jornal A Gazeta Literária do Porto, dirigido por Camilo Castelo Branco, o periódico teve vida curta apenas 16 números. Contudo, conta com a vasta participação de Ana sob o pseudónimo Gastão Vidal de Negreiros. Além das críticas literárias em formato de cartas, que eram dirigidas a Camilo, Ana também publicou o romance Regina que ficou incompleto. De acordo com Adriana Mello Guimarães (2020):

uma das mais interessantes componentes da técnica narrativa das suas críticas, que construiu um inovação, é o gênero epistolar. As cartas trocadas entre Gastão Vidal de Negreiros e Camilo Castelo Branco recorrem a um tom confessional que introduz recursos expressivos com simplicidade. Para além de servirem de elemento de comunicação com o público, contribuem para a percepção de estarmos a assistir um diálogo entre amigos. (GUIMARÃES, 2020, p. 72). 
Em 1871, Ana Plácido publica o seu segundo livro, Herança de Lágrima sob o pseudônimo de Lopo de Sousa. Uma obra "dotada de grande profundidade psicológica, e porventura a sua composição mais conseguida” (ALONSO, 2014, p. 42). De acordo com Fábio Mário da Silva (2020):

Nesse romance, as escolhas que as mulheres devem tomar em relação ao comportamento moral e às satisfações amorosas esbarram em dilemas que desnorteiam as personagens femininas. Herança de lágrimas tem o seu enredo centrado em duas partes e numa conclusão, concentrando-se na estória de duas mulheres, mãe e filha, em dois períodos e épocas diferentes, retomando uma narrativa passada para se entender as consequências futuras na vida da personagem principal, Diana. Essa estratégia utilizada por Ana Plácido se chama analepse ou flash-back. Através de uma narrativa analéptica e secundária, recuperase informação anterior ao presente da narrativa principal, com a finalidade estética de desenvolver a diegese entretecida através de uma dimensão diacrônica do tempo. (SILVA, 2020, p. 144).

Cremos, assim, que Ana Augusta Plácido não se contentou apenas em inserir personagen femininas nas suas histórias, o que a escritora fez foi incutir nas suas criações a perspectiva do olhar e da experiência destas personagens enquanto mulheres. Desta forma, produziu não apenas a linguagem poética, mas também metalinguagem e reflexão sobre a linguagem com uma consciência elevada do que representava, naquele período, ser mulher e no caso dela, em específico, ser uma mulher escritora.

\section{Conclusões}

Apesar de suas publicações tão relevantes para a história da literatura portuguesa, a produção artística de Ana Plácido não foi suficiente para evitar seu cíclico apagamento. Cremos que o fato de ser mulher foi decisivo para seu apagamento ainda no século XIX, mas a contribuição maior deve-se ao relacionamento com Camilo Castelo Branco, escritor prestigiado e reconhecido. Ana foi aos poucos apagada e esquecida no campo literário, enquanto ficava conhecida como 'amor de perdição' ou a 'mulher fatal' de Camilo. Para Maria Amélia Campos (2008), não é possível confirmar se Camilo acreditava no talento da amada, mas:

Que Ana lhe deu muito jeito na sua parceria literária, não restam quaisquer dúvidas, quer na participação no Mundo Elegante - que parece ter significado mais do que uma simples ajuda no mundo da escrita - quer em todo o trabalho que vieram a desenvolver juntos. (CAMPOS, 2008, p. 221).

Sobre participação das mulheres na literatura, cremos que Camilo e Ana tinham visões muito distintas neste aspecto, Camilo tinha alguma dificuldade para se libertar das imposições sociais atribuídas as mulheres do século XIX e isto pode ser confirmado na correspondência trocada entre Luís Augusto Palmeirim e o escritor. Palmeirim envia uma carta, contando do seu desejo em publicar uma obra sobre poetisas portuguesas daquele século, crendo que para que tal estudo fosse completo era necessário que constasse o nome de Ana Plácido. Por esta razão solicita ao amigo que lhe envie mais informações sobre as publicações da escritora. Camilo responde da seguinte forma:

Ana Plácido, além de Luz coada por Ferros, escreveu o romance Herança de Lágrimas com o pseudónimo de Lopo de Sousa, e com o mesmo pseudónimo traduziu três volumes de romances franceses: A vergonha de matar, Como as mulheres se perdem e Feitiços da mulher que te mando Escreveu na Gazeta literária do Porto. Ela se confessa arrependida de todos estes pecados, e te pede que não a menciones se não pelo pseudónimo. Isto é sério. (Castelo Branco, 1943, p. 9, grifo nosso).

Não cremos que esta era a opinião de Ana Plácido, pois sabemos que a literatura ocupou um papel muito importante na sua trajetória, além disso, Ana Plácido dedicou-se a literatura até seus últimos dias, portanto, estaria longe de considerá-la pecado. Cremos sim, que esta era a visão de Camilo Castelo Branco sobre as mulheres e que estava alinhado ao contexto do século XIX em que a condição feminina estava baseada no pudor, na modéstia e na subalternização.

Por outro lado, a relevante contribuição de Ana Plácido na obra de Camilo Castelo Branco é 
reconhecida pelos críticos e estudiosos do autor. Em seus últimos anos de vida, Camilo já estava muito doente e andava sempre a viajar de cidade em cidade em busca da opinião de médicos que lhe dessem esperança de cura. Camilo nesta altura já mal podia ler, visto que em virtude de sua enfermidade foi perdendo gradualmente a visão. Conforme nos explica Campos (2008):

A ideia de que Camilo se isolou em Ceide a plantar couve-galega é um mito. Camilo contactava com grandes intelectuais do seu tempo, poetas, escritores, políticos, condes, barões, viscondes e barões, assinava inúmeros periódicos, e não regateava livros que lhe trouxessem mais conhecimento. Aliás, vida de andarilho que levava, pouco consentânea com as suas constantes dores e achaques que, segundo dizia, o retinham no leito, não era propícia a abundante obra literária que legou ao país. A menos que Ana Plácido tenha sido muito mais do que a sua mulher fatal, a sua amante querida, a sua enfermeira e assistente, e aquela de quem se enfadou. A menos que tenha sido mais autora do que assistente e tenha produzido muito mais obra do que a que veio a conhecimento do público. (CAMPOS, 2008, p. 221).

Não podemos confirmar a hipótese defendida por Campos (2008), apesar de concordarmos com a sua argumentação coerente que compara a vasta produção do escritor e seu estado de saúde. Nesta pesquisa contudo, preferimos dar maior relevância a produção afirmada por Ana Plácido, visto que é através dela que podemos confirmar que a autora usa a escrita para refletir sobre os acontecimentos ocorridos em sua vida, e isto faz com que se perceba e se reconheça de outras formas formando assim a sua consciência, mas também ao que ia sucedendo na sociedade, não se apresentando como produto do meio, mas como fator da sua transformação Ana Plácido, ao refazer a sua trajetória, forma a sua consciência com o processo de autoanálise a partir da escrita, mas também a consciência do seu gênero (o feminino), silencioso e silenciado.

\section{Referências}

ALONSO, Cláudia Pazos. Ana Plácido, uma escritora oitocentista exemplar. In: PRETOV, Petar et al (Org.) Avanços em Literatura e Cultura portuguesas. Da Idade Média ao século XIX. Santiago de Compostela, Faro: Associação Internacional dos Lusitanistas e Através Editora, 2012. p. 249-266.
ALONSO, Cláudia Pazos. A trajetória literária de Ana Plácido e o papel de Camilo. In: SOUSA, Sérgio Guimarães de. Representações do feminino em Camilo Castelo Branco. Vila Nova de Famalicão, Casa Camilo:Centro de estudos Camilianos, 2014. p. 39-64.

CABRAL, Fernanda Damas. Ana Plácido. Estudo, cronologia, antologia (narrativa). Lisboa: Caminho, 2012.

CABRAL, Fernanda Damas. Ana Plácido. In: FERRAZ, Maria de Lourdes A. (Coord.) Dicionário de Personagens da Novela Camiliana. Lisboa: Caminho, 2002. p. 422-423.

CAMPOS, Maria Amélia. Ana, a Lúcida. Biografia de Ana Plácido. Lisboa: Parceria A. M. Pereira, 2008.

CASTELO BRANCO, Camilo. Sete cartas de [...] a Luís Augusto Palmeirim. Oldemiro César (compilação). Lisboa: Império, 1943.

CASTRO, J. C. Vieira de, Camillo Castello Branco. Noticia da sua vida e obra. 2. ed. Porto: Graphica de António José da Silva Teixeira, 1863.

CASTRO, Aníbal Pinto. Ana Plácido, a 'heroína' de Camilo. In: A Mulher na Vida e Obra de Camilo, Braga, Câmara Municipal de Vila Nova de Famalicão/Centro de Estudos Camilianos, 1997.

O NACIONAL, semanario politico, commercial, noticioso e critico. Porto: Typographia Alliança, 1860

PLÁCIDO, Ana. Luz coada por ferros / Herança de Lágrimas. Edição facsimilada. Vila Nova de Famalicão: Lello \& Irmãos Editores/ Câmara Municipal de Vila Nova de Famalicão, 1995.

SILVA, Fabio Mario da. Os dilemas femininos no romance «Herança de lágrimas», de Ana Plácido. 2020. Disponível em: <https://e-lcv.online/index.php/revista/issue/view/5>. Acesso em: 2 abr. 2021.

WOOLF, V. Um teto todo seu. Tradução de Bia Nunes de Sousa e Glauco Mattoso. 1. ed. São Paulo: Tordesilhas, 2014 